\title{
INFLUÊNCIA DAS OPERAÇÕES SOBRE O BAÇO NA DISTRIBUIÇÃO DA ESCHERICHIA COLI NO SISTEMA MONONUCLEAR FAGOCITÁRIO
}

\author{
INFLUENCE OF SURGICAL PROCEDURES ON SPLEEN ON DISTRIBUTION OF \\ ESCHERICHIA COLI IN MONONUCLEAR PHAGOCYTE SYSTEM
}

\author{
Rodrigo Gomes da Silva ${ }^{1}$ \\ Andy Petroianu, TCBC - MG $^{2}$ \\ Marconi Gomes da Silva ${ }^{3}$ \\ Simone Odília Fernandes Diniz ${ }^{4}$ \\ Valbert Nascimento Cardoso ${ }^{5}$
}

\begin{abstract}
RESUMO: Objetivos: Para se evitar o estado asplênico, muitas medidas preservadoras do baço têm sido propostas na literatura, como a esplenorrafia, a esplenectomia parcial com preservação dos vasos hilares e o auto-implante de tecido esplênico. A esplenectomia subtotal, com conservação do pólo superior do baço, nutrido apenas pelos vasos esplenogástricos é uma alternativa quando o pedículo esplênico precisa ser ligado. O objetivo deste estudo foi avaliar a influência das esplenectomias parcial, subtotal e total na distribuição da Escherichia coli no sistema mononuclear fagocitário. Método: Foram estudados 32 ratos divididos em 4 grupos: operação simulada (mantendo todo o baço), esplenectomia parcial, esplenectomia subtotal e esplenectomia total. Após cinco semanas da operação, uma alíquota de Escherichia coli marcada com 99mtecnécio foi injetada por via venosa. Após 20 minutos, os animais foram mortos, e o baço, os pulmões e o fígado foram retirados para se verificar a distribuição das bactérias marcadas. Resultados: A quantidade de Escherichia coli no tecido esplênico foi maior no grupo com o baço íntegro em comparação com os grupos esplenectomia parcial e subtotal. A distribuição da bactéria marcada pelo baço não diferiu nos grupos com esplenectomia parcial ou subtotal. A quantidade de bactérias no pulmão foi maior no grupo esplenectomia parcial do que a do grupo com esplenectomia subtotal. Após esplenectomia subtotal, a distribuição da bactéria marcada foi maior no fígado em comparação com a captação desse órgão nos demais grupos. Conclusões: $\mathrm{O}$ pólo superior do baço, suprido apenas pelos vasos esplenogástricos, tem capacidade de remover da circulação bactérias vivas, mostrando que, mesmo sem a vascularização pelo pedículo esplênico, há uma eficiente depuração sangüínea. A distribuição da Escherichia coli pelo sistema mononuclear fagocitário apresenta comportamentos diferentes, dependendo do tipo de esplenectomia a que o animal é submetido.
\end{abstract}

Descritores: Bactéria marcada; Baço; Esplenectomia; Esplenectomia parcial; Esplenectomia subtotal; Sistema mononuclear fagocitário

1. Professor Adjunto do Departamento de Cirurgia da Faculdade de Medicina, UFMG; Doutor em Cirurgia pela Faculdade de Medicina da UFMG; Cirurgião do Serviço de Gastroenterologia, Nutrição, Cirurgia Geral e do Aparelho Digestivo (GEN-CAD) do Hospital das Clínicas, UFMG.

2. Professor Titular do Departamento de Cirurgia da Faculdade de Medicina, UFMG; Docente-Livre de Técnica Operatória e Cirurgia Experimental da Escola Paulista de Medicina, UNIFESP; Docente-Livre de Gastroenterolgia Cirúrgica da Faculdade de Medicina de Ribeirão Preto, USP; Doutor em Fisiologia e Farmacologia pelo Instituto de Ciências Biológicas, UFMG; Pesquisador IA do CNPq.

3. Médico formado pela Faculdade de Medicina da UFMG; Ex-bolsista da Fapemig.

4. Professora Assistente do Departamento de Análises Clínicas e Toxológicas (Laboratório de Radioisótopos) da Faculdade de Farmácia, UFMGMestre em Ciências Farmacêuticas pela Faculdade de Farmácia, UFMG

5. Professor Adjunto do Departamento de Análises Clínicas e Toxológicas (Laboratório de Radioisótopos) da Faculdade de Farmácia, UFMG; Doutor em Ciências Nucleares pela Universidade de São Paulo, USP-SP.

Trabalho realizado no Departamento de Técnica Operatória e Cirurgia Experimental da Universidade Federal de Juiz de Fora e no Departamento de Anatomia Patológica da Universidade de Alfenas 


\section{INTRODUÇÃO}

Pacientes esplenectomizados têm maior susceptibilidade a desenvolver infecções fulminantes caracterizadas por bacteremia, meningite ou pneumonia. Bardach ${ }^{1}$, no final do século XIX, foi um dos primeiros a mostrar experimentalmente que a ausência do baço provocava a morte por sepse. Entretanto, somente após a publicação do artigo de King e Shumacker Jr. ${ }^{2}$, em 1952, no qual foi descrita sepse fulminante em cinco crianças esplenectomizadas, a comunidade médica despertou para os riscos do estado asplênico. Nos anos seguintes, numerosas publicações, experimentais e clínicas, comprovaram que a ausência do baço aumenta o risco de infecções graves.

A sepse pós-esplenectomia pode ser explicada pela disfunção imunológica, visto que o tecido esplênico perfaz $25 \%$ da massa linfóide e da capacidade fagocitária do organismo ${ }^{3}$. A retirada do baço resulta em perda parcial da filtração de antígenos oriundos da corrente sangüínea, além de diminuir a produção de opsoninas (anticorpos, principalmente IgM, fatores do complemento, tuftsina, properdina etc.) e a ativação linfocitária. Os macrófagos do baço são capazes de remover bactérias do sangue, mesmo na ausência de opsoninas, e protegem o organismo de processos sépticos graves, tendo um papel maior na infecção aguda.

Diante da importância do baço, tem sido aceito que se deva tentar a preservação esplênica sempre que esse procedimento for possível sem comprometer o tratamento ou prejudicar o doente ${ }^{4,5}$. De acordo com a literatura, para se manter a viabilidade do baço, é necessário preservar o pedículo vascular esplênico intacto. Entretanto, estudos prévios $^{6}$, mostraram que o pólo superior do baço apresenta vascularização própria: os vasos esplenogástricos, que não dependem do pedículo esplênico. Desse modo, afecções em que o pedículo esplênico não puder ser preservado, como ocorre no trauma maior do baço, podem ser tratadas adequadamente mantendo seu pólo superior suprido pelos vasos esplenogástricos ${ }^{7}$. Essa operação é denominada esplenectomia subtotal, diferenciando da esplenectomia parcial, que requer a preservação do pedículo esplênico.

Por outro lado, mesmo provando-se a viabilidade do baço, surgem dúvidas quanto à sua função, principalmente no que diz respeito à remoção de bactérias da circulação. Segundo a literatura, as funções esplênicas somente seriam adequadas se fosse mantido o pedículo vascular do órgão ${ }^{4}$. Mesmo tendo sido verificado que o pólo superior do baço, suprido apenas pelos vasos esplenogástricos, era capaz de remover substâncias coloidais da circulação sangüínea, ainda persistia a dúvida se o remanescente esplênico seria capaz de manter esse papel em relação a bactérias, que é o objetivo mais importante dessa operação sob ponto de vista clínico.

Nesse sentido, o presente estudo foi conduzido para verificar a importância do pedículo vascular esplênico na função fagocitária de remanescentes esplênicos das esplenectomias subtotal e parcial. Destaca-se ainda a importância de verificar se as esplenectomias total, parcial e subtotal interferem no padrão de distribuição bacteriana pelos principais órgãos do sistema mononuclear fagocitário (baço, pulmão e fígado).

\section{MÉTODO}

Os animais foram tratados conforme as normas éticas de utilização de animais em pesquisa.

Foram estudadas 32 ratas, da raça Wistar, pesando entre $206 \mathrm{~g}$ e $269 \mathrm{~g}$. Os animais permaneceram em número de quatro ratos por gaiola e receberam ração apropriada para ratos, além de água $a d$ libitum.

Não houve jejum pré-operatório e não se utilizou técnica asséptica nas operações. Os procedimentos cirúrgicos foram conduzidos sob anestesia com éter etílico. Os animais foram divididos nos seguintes grupos:

Grupo I: Operação simulada, com baço íntegro. $\mathrm{O}$ baço foi mobilizado medialmente e recolocado intacto no hipocôndrio esquerdo.

Grupo II: Esplenectomia total. Após ligadura de todos os vasos esplênicos com fio de categute 5-0, o baço foi completamente removido.

Grupo III: Esplenectomia parcial. Após identificação do pedículo esplênico, ligaram-se apenas os vasos segmentares caudais com fio de categute 5-0. Os dois terços caudais do baço foram ressecados e a hemostasia da borda seccionada foi realizada com um ponto em X, utilizando categute simples 5-0, montado em agulha cilíndrica.

Grupo IV: Esplenectomia subtotal. Após a mobilização do baço medialmente, procedeu-se à ligadura do pedículo esplênico com categute simples 
5-0. Os vasos esplenogástricos foram identificados e cuidadosamente preservados. Os dois terços caudais do baço foram ressecados. A hemostasia do remanescente esplênico foi realizada com um ponto em $X$ de categute simples 5-0 montado em agulha cilíndrica.

A bactéria utilizada foi a Escherichia coli (ATCC-10536 ; American Type Culture Collection, Rockville, EUA). Sua marcação seguiu a técnica descrita e padronizada por Diniz et al. ${ }^{8}$ A concentração bacteriana foi ajustada por meio de espectrofotômetro em porcentagem de transmitância a $580 \mathrm{~nm}$, que corresponde a aproximadamente $10^{8}$ unidades formadoras de colônia por mililitro (UFC/ml).

Após cinco semanas da operação, os animais foram anestesiados com éter etílico e, após limpeza da cauda com água e sabão neutro, injetaram-se, em uma veia da cauda, 2 microlitros da suspensão de Escherichia coli marcada com 99m-tecnécio (99mTc).

Após a injeção da $99 \mathrm{mTc}-E$. coli, cada animal permaneceu durante 20 minutos em uma gaiola individual e, em seguida, após anestesia com éter, o rato foi decapitado com auxílio de uma guilhotina. Realizou-se uma incisão toracoabdominal mediana para permitir a retirada dos pulmões, fígado e baço. Esses órgãos foram pesados em balança de precisão e seccionados em pequenos pedaços, permitindo sua introdução em tubos de ensaio.

As contagens foram realizadas em um cintilador automático tipo poço. Utilizou-se para efeito de cálculo um padrão de dose. Esse padrão continha o mesmo volume e a mesma atividade de $99 \mathrm{mTc}-E$. coli injetada nos animais para a realização dos experimentos. A contagem do padrão foi considerada $100 \%$ de radioatividade injetada nos animais. Dessa forma, a porcentagem de captação da 99mTc- E. coli foi calculada com a seguinte equação:

$\%$ de captação $=\frac{\text { cpm órgão }}{\text { cpm padrão }} \times 100$

Com relação à porcentagem de captação da $99 \mathrm{mTc}-E$. coli no tecido esplênico, os resultados também foram expressos em cpm/grama de tecido, levando em consideração o peso do baço. Desse modo, a radioatividade $(\mathrm{cpm})$ presente em todo o baço foi dividida pelo peso em grama do órgão.

\author{
cpm (radioatividade) \\ $\mathrm{cpm} / \mathrm{g}=\frac{\text { peso total do baço (grama) }}{\text { gens }}$ \\ cpm: contagens por minuto
}

A avaliação da porcentagem captada pelo sistema mononuclear fagocitário dos pulmões, fígado e baço com relação aos quatro grupos de interesse foi realizada utilizando a técnica de análise de variância, comparando as médias. Quando a análise mostrou a existência de diferença, realizaram-se as comparações múltiplas de médias segundo o teste LSD (least significance difference).

Os resultados foram considerados significativos para o nível de significância de $5 \%$ $(\mathrm{p}<0,05)$.

\section{RESULTADOS}

Os animais evoluíram bem no pós-operatório, retornando às mesmas condições do pré-operatório. Todos animais incluídos apresentavam-se ativos e sadios no momento da inoculação das bactérias.

Observa-se na Figura-1 uma distribuição maior da E. coli no baço íntegro, ao ser comparado com o submetido a esplenectomia parcial e esplenectomia subtotal ( $\mathrm{p}<0,0001)$. Não houve diferença entre as distribuições nos baços remanescentes de esplenectomia parcial e subtotal. Mesmo quando se avalia a distribuição esplênica da bactéria por grama de tecido, observa-se que o grupo com o baço íntegro apresentou maior captação do que a encontrada nos remanescentes de esplenectomia parcial e subtotal $(\mathrm{p}<0,0141)$ (Tabela-1).

Com relação à distribuição da $99 \mathrm{~m} T c-E$. coli no tecido pulmonar, os resultados obtidos mostraram uma quantidade maior nos animais com esplenectomia parcial e menor no grupo da esplenectomia subtotal $(\mathrm{p}<0,05)$ (Figura-1).

A distribuição da $99 \mathrm{mTc}-E$. coli no fígado foi maior no grupo da esplenectomia subtotal quando comparado com os demais grupos $(\mathrm{p}<0,0001)$ (Tabela-2).

\section{DISCUSSÃO}

Apesar de comprovado que o remanescente esplênico de animais submetidos à esplenectomia subtotal é capaz de fagocitar colóide e hemácias, e assim presumir que sua função imunológica estaria preservada, a capacidade de reter bactérias prec- 


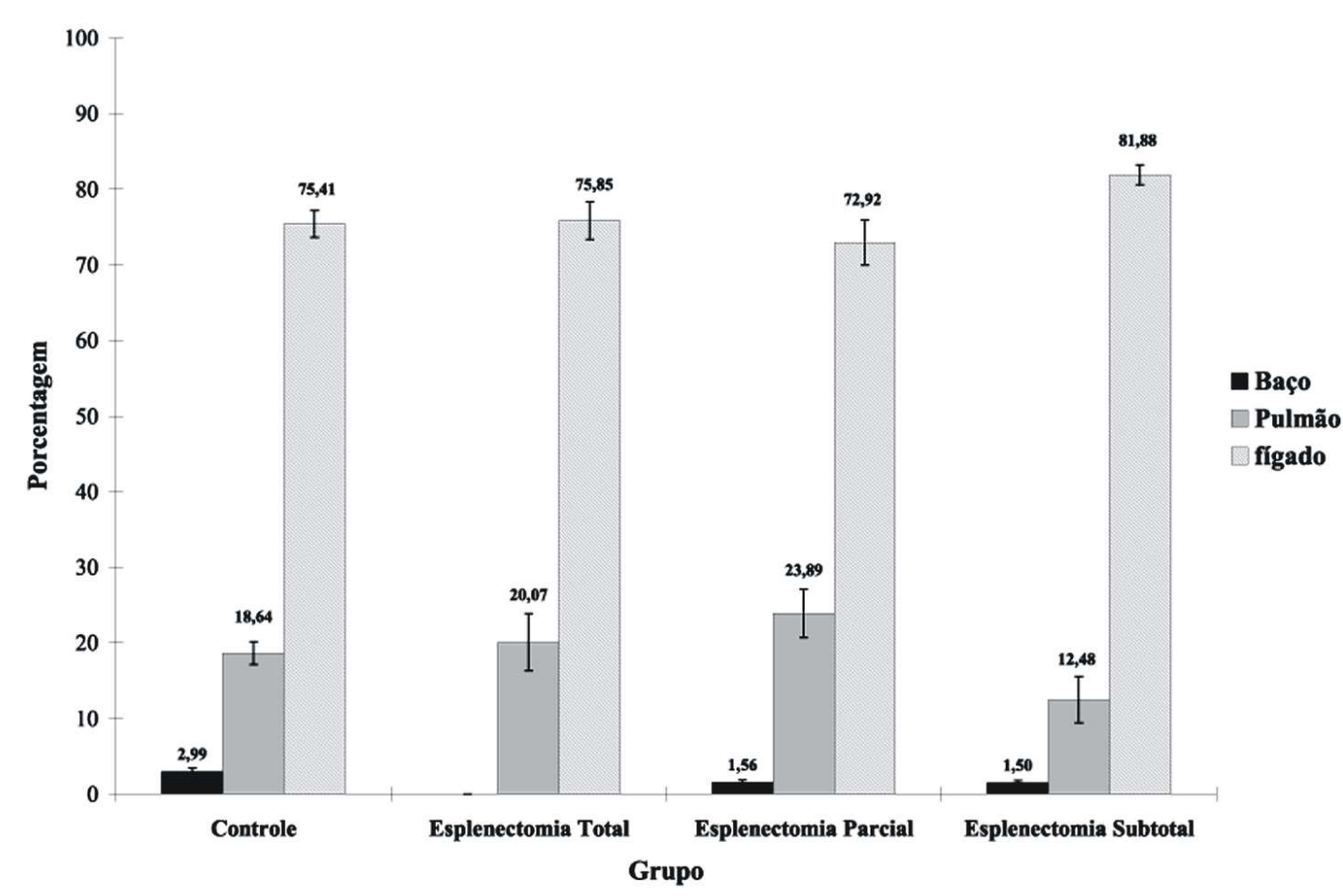

Figura 1 - Distribuição porcentual da E. coli marcada com 99m-Tecnécio no baço, pulmão e fígado de rato.

isava ser conhecida ${ }^{9,10}$. Ademais, a distribuição da bactéria Gram-negativa pelo sistema mononuclear fagocitário em ratos submetidos a essa cirurgia conservadora do baço ainda não havia sido estudada.

A Escherichia coli foi escolhida para este trabalho por ser ela responsável por sepse fulminante pós-esplenectomia em $13 \%$ dos pacientes ${ }^{10} \mathrm{e}$ predominar nas infecções de pacientes imunodeprimidos ${ }^{11,12}$. Estudos experimentais mostraram que animais asplênicos são mais susceptíveis a infecção por bactérias Gram-negativas. Almdahl et al. ${ }^{13}$ submeteram ratos à injeção de Escherichia coli por via venosa ou peritoneal e observaram que animais submetidos à esplenectomia tiveram a depuração dessas bactérias no sangue prejudicada quando comparados com ratos normais. Outros estudos ${ }^{14}$ indicaram que ratos esplenectomizados foram incapazes de depurar a bactéria da corrente sangüínea. No presente estudo, após cinco semanas, os animais foram submetidos à inoculação da bactéria marcada. A escolha desse período seguiu a orientação de trabalhos prévios na mesma linha de pesquisa ${ }^{11}$.

Não ocorreu infecção pós-operatória nos animais submetidos às operações, apesar de as condições cirúrgicas não terem sido assépticas. Essa baixa taxa

Tabela 1 - Quantidade de 99mTc-E. coli presente em baço íntegro ( Grupo I) ou de remanescente de esplenectomia parcial (Grupo III) ou subtotal (Grupo IV), medida em contagens por minuto/grama de tecido.

\begin{tabular}{lccccc}
\hline Grupo & Mínimo & Máximo & $\begin{array}{c}\text { Medidas descritivas } \\
\text { Média }\end{array}$ & Desvio padrão & p \\
\hline I & 138158,0 & 221061,0 & 179974,3 & 27385,8 & 0,0141 \\
III & 124238,0 & 185755,0 & 147912,8 & 21271,1 & \\
IV & 102414,0 & 179851,0 & 140444,6 & 28498,0 & I > III = IV \\
\hline
\end{tabular}

O valor de p na tabela refere-se ao teste da análise de variância para os 3 grupos 
Tabela 2 - Quantidade de 99mTc-E. coli presente nos fígados dos Grupos com baço íntegro (Grupo I), sem o baço (Grupo II), com remanescente de esplenectomia parcial (Grupo III) ou esplenectomia subtotal (Grupo IV), medida em \% dosel padrão.

\begin{tabular}{lccccc}
\hline \multirow{2}{*}{ Grupo } & \multicolumn{5}{c}{ Medidas descritivas } \\
& Mínimo & Máximo & Média & Desvio padrão & p \\
\hline I & 72,36 & 79,00 & 75,41 & 2,65 & 0,0001 \\
II & 70,50 & 71,21 & 75,85 & 3,58 & IV $>$ I=II=III \\
III & 66,75 & 80,68 & 72,92 & 4,37 & \\
IV & 80,00 & 84,77 & 81,88 & 1,90 & \\
\hline
\end{tabular}

O valor de p na tabela refere-se ao teste da análise de variância para os 4 grupos.

de infecção nas operações em ratos tem sido observada em nosso laboratório ao longo dos anos e por isso não utilizamos condições rigorosas de assepsia. Verificamos também que a maior parte dos trabalhos da literatura não realiza operações em ratos com os rigores da antissepsia cirúrgica, sem que o fato interfira aparentemente nos resultados. Além disso, o momento escolhido para injeção da bactéria marcada foi suficientemente adequado para diagnosticar uma eventual infecção que pudesse influenciar na distribuição bacteriana pelo sistema mononuclear fagocitário. Devemos ainda destacar que, ao reoperarmos os animais para retirada dos órgãos do sistema mononuclear fagocitário, não constatamos sinais de sepse.

A quantidade de tecido esplênico remanescente é importante para a manutenção do papel imunológico e prevenção da sepse fulminante pósesplenectomia. Van Wick et al. ${ }^{15}$ mostraram que, quanto maior o remanescente esplênico, maior a quantidade de bactéria necessária para matar os ratos, portanto, maior quantidade de tecido remanescente esplênico, acompanha-se de melhor proteção contra sepse. A quantidade mínima de tecido esplênico com função fagocitária suficiente e adequada é de $25 \%$ do baço normal de cada espécie animal. Um terço do baço foi considerado eficaz para restaurar a resistência do hospedeiro a infecção por Streptoccus pneumonie tipo III $^{16}$.

No presente estudo, tanto nos animais submetidos à esplenectomia parcial (preservando a irrigação do pedículo esplênico) quanto nas ratas submetidas a esplenectomia subtotal (sem irrigação do pedículo esplênico) foi possível preservar o equivalente a um terço do baço, sem prejuízo da sua vitalidade. Desse modo, utilizamos remanescentes esplênicos que não diferiam quanto ao peso.
A utilização de bactéria marcada testa melhor a capacidade fagocitária do que a substância coloidal, tendo em vista que a depuração de bactérias é mais complexa do que a de substâncias inanimadas ${ }^{17-21}$. Acredita-se que para uma função adequada do remanescente esplênico, o suprimento sangüíneo fornecido pela artéria esplênica seja essencial. Horton et al. ${ }^{22}$ relataram uma depuração do pneumococo mais demorada quando a artéria esplênica foi ligada, provavelmente devido à diminuição do fluxo sangüíneo. Cooney et al. ${ }^{23}$ mostraram que a esplenectomia parcial é mais eficiente na depuração bacteriana, quando comparada com grupo de animais submetidos a auto-implante, provavelmente por terem os auto-implantes menor suprimento sangüíneo.

Por outro lado, no presente estudo, a presença da 99mTc-Escherichia coli no baço não diferiu no grupo submetido a esplenectomia parcial quando comparado com o da esplenectomia subtotal. O provável fluxo sangüíneo mais lento no remanescente da esplenectomia subtotal pelo vasos esplenogástricos, devido à falta da irrigação do pedículo, poderia talvez permitir um maior contato antígeno-células fagocitárias, compensando assim a redução do fluxo sangüíneo. Dessa forma, haveria uma maior eficácia fagocitária no remanescente da esplenectomia subtotal.

O fígado é o maior órgão do sistema mononuclear fagocitário e, como esperado, foi o tecido que deteve a maior quantidade de bactérias marcadas, apesar de o primeiro órgão de contato do inóculo ter sido o pulmão. A distribuição da $E$. coli no fígado variou entre $72,92 \%$ da dose-padrão, no grupo esplenectomia parcial, e $81,88 \%$ da dose-padrão, no grupo esplenectomia subtotal. $\mathrm{O}$ grupo submetido à esplenectomia subtotal foi o que apresentou maior captação no fígado quando comparado com os outros 
três grupos. Provavelmente ocorreu uma compensação do sistema mononuclear fagocitário quando os animais foram submetidos a esse prcedimento sobre o baço.

Em conformidade com os dados do presente estudo, pode-se concluir que os baços remanescentes, tanto da esplenectomia parcial, mantendo o pedículo vascular principal, quanto da esplenectomia subtotal, com manutenção apenas dos vasos esplenogástricos, são capazes de remover a Escherichia coli. Portanto, o pedículo esplênico não é indispensável para que o baço remanescente exerça a sua função depuradora de bactérias da circulação sangüínea.

\begin{abstract}
Background: To avoid asplenic state, many approaches preserving the spleen have been proposed, such as splenorraphy, partial splenectomy with hilum vessels preservation and autotransplantation. Subtotal splenectomy preserving the upper splenic pole supplied only by splenogastric vessels, is an alternative when splenic pedicle cannot be maintained. The purpose of this study is to evaluate the influence of partial, subtotal and total splenectomy on Escherichia coli distribution in mononuclear phagocyte system. Methods: Thirty-two rats were divided into the following 4 groups: sham operation (no splenectomy), partial splenectomy, subtotal splenectomy and total splenectomy. In the fifth week postoperative, an aliquot of Escherichia coli labelled with technetium-99m was intravenously injected. After 20 minutes, the animals were killed to remove spleen, lungs and liver, in order to verify the labelled bacteria distribution. Results: The amount of Escherichia coli in the splenic tissue was greater in the group with intact spleen. The bacteria uptake by the spleen was not different from partial or subtotal splenectomy groups. The amount of bacteria in the lungs was greater in the partial splenectomy group than in the subtotal group. After subtotal splenectomy, the distribution of labelled bacteria was greater in the liver than in the others all groups. Conclusions: The upper splenic pole, supplied only by splenogastric vessels, is able to remove alive bacteria from the blood stream, showing that, even in absence of splenic pedicle, blood clearance continues to be effective. The distribution of Escherichia coli in mononuclear phagocyte system shows different behaviors, depending on the type of splenectomy.
\end{abstract}

Key words: Escherichia coli; Spleen; Splenectomy; Partial splenectomy; Subtotal splenectomy; Mononuclear phagocyte system

\section{REFERÊNCIAS}

1. Bardach (1891) apud Morris DH, Bullock FD - The importance of the spleen in resistence to infection. Ann Surg, 1919, 70:513-521.

2. King H, Shumacker Jr, HB - Susceptibility to infection after splenectomy performed in infancy. Ann Surg, 1952, 136:239-242.

3. Llende M, Santiago EA, Lavergne J - Immunological consequences of splenectomy. J Surg Res, 1986, 40:8594.

4. Pachter HL, Grau J - The current status of splenic preservation. Adv Surg, 2000, 34:137-174.

5. Rezende V, Petroianu A - Estado funcional tardio do auto-implante esplênico após trauma complexo do baço humano. Rev Bras Col Cir, 2001, 28:165-170.

6. Petroianu A, Ferreira VL, Barbosa AJ -Morphology and viability of the spleen after subtotal splenectomy. Brazilian J Med Biol Res, 1989, 22:491-495.
7. Rezende V, Petroianu A- Subtotal splenectomy for treatment of severe splenic injuries. J Trauma, 1998, 44:933935.

8. Diniz SO, Resende BM, Numan EA et al. - 99m-Technetium labelled Escherichia coli. Appl Radiat Isot, 1999, 51:33-36.

9. Petroianu A, Simal CJ, Barbosa, AJ - Splenic macrophage phagocytic function after subtotal splenectomy in the dog. Med Sci Res, 1992, 20:127-128.

10. Petroianu A, Barbosa AJ - Quantitative studies on macrophages phagocytosis in whole spleen and in remnant of subtotal splenectomy. Med Sci Res, 1991, 19:373-375.

11. Petroianu A, Simal CJ, Barbosa AJ - Assesment of phagocytic function in remnants of subtotal splenectomy and in autologous spleen implantation. Med Sci Res, 1993, 21:715-717.

12. Singer D - Postsplenectomy sepsis. Perpect Pediatr Pathol, 1973, 1:285-311. 
13. Almdahl SM, Bogwald J, Hoffman J, et al. - The effect of splenectomy on Escherichia coli sepsis and its treatment with semisoluble aminated glucan. Scand J Gastroenterol, 1987, 22:261-267.

14. Scher KS, Wroczynsky F, Coil JA - The effect of splenectomy on gram-negative bacteremia. J Trauma, 1982, 22:407-409.

15. Van Wyck DB, Witte MH, Witte CL, et al. - Critical splenic mass for survival from experimental pneumococcemia. J Surg Res, 1980, 28:14-17.

16. Bradshaw PH, Thomas CG - Regeneration of splenic remnants after partial splenectomy in rats. J Surg Res, 1982, 32:176-181.

17. Scott-Conner CE, Bernstein JM, Scher KS, et al. - The effect of biliary obstrution on a gram-negative bacteremic challenge. Surgery, 1986, 99: 680-683.

18. Scher KS - Splenic preservation using upper short gastric vessels. Am J Surg, 1985, 170:304.

19. Andersson R, Foss A - Abdominal sepsis following liver resection in the rat. Hepato-Gastroenterol, 1991, 38:547-549.
20. Katz S, Merkel GJ, Folkening WJ, et al. - Blood clearance and organ localization of Candida albicans and E coli following dual infection in rats. J Pediat Surg, 1993, 28:329-333.

21. Bowdy BD, Aziz SM, Marple SL, et al. - Organ-specific disposition of group B Streptococci in piglets. Pediatr Res, 1990, 27:344-348.

22. Horton J, Ogden ME, Willians S, et al. - The importance of splenic blood flow in clearing Pneumococcal organism. Ann Surg, 1982, 195:172-176.

23. Cooney DR, Dearth JC, Swanson SE et al. - Relative merits of partial splenectomy, splenic reimplantation and immunization in preventing postsplenectomy infection. Surgery, 1979, 86:561-569.

Endereço para correspondência:

Prof. Andy Petroianu

Av. Afonso Pena, 1626 Apto 1901

30130-005 - Belo Horizonte - MG

Fone/Fax: 55 + 31 3274-7744

E-mail: petroianu@medicina.ufmg.br 